\title{
Alterations in cadherin and catenin expression during the biological progression of melanocytic tumours
}

\author{
D S A Sanders, K Blessing, G A R Hassan, R Bruton, J R Marsden, J Jankowski
}

Department of Histopathology, University Hospital Birmingham Trust, Edgbaston,

Birmingham B15 2TT, UK

D S A Sanders

G A R Hassan

Department of Dermatology, University Hospital Birmingham Trust J R Marsden

Department of Histopathology, Worthing Hospital, Worthing, BN11 2DH, UK

K Blessing

Epithelial Biology Laboratory, Institute for Cancer Studies and Department of Medicine, University of Birmingham, Birmingham B15 2TJ, UK

R Bruton

J Jankowski

Correspondence to: Dr DSA Sanders, Department of Pathology, The Medical School, Edgbaston, Birmingham B15 2TT, UK

e-mail:

d.s.a.sanders@bham.ac.uk

Accepted for publication 23 February 1999

\begin{abstract}
Aims-Compelling evidence from cell culture studies implicates cadherins in the neoplastic progression of melanocytic tumours but few reports describe the expression of cadherins and the related transmembrane proteins, catenins, in a full range of benign and malignant excised melanocytic tumours.
\end{abstract}

Methods-Using immunohistochemistry and western blotting after tissue fractionation, the pattern of expression of cadherins/ catenins was studied in a range of surgically excised melanocytic tumours, from dysplastic naevi to stage III cutaneous metastatic malignant melanoma.

Results-Appropriate membranous expression of E-cadherins and P-cadherins is seen in dysplastic naevocytes with an epithelioid phenotype and is largely maintained with malignant transformation to radial growth phase melanoma and primary vertical growth phase malignant melanoma. Loss of membranous E-cadherin is seen in a small number of vertical growth phase melanomas only when metastasis has occurred. However, there is a concomitant dramatic loss of membranous $\mathbf{P}$-cadherin expression in all melanomas at the same stage. A minority of metastatic melanomas show de novo membranous $\mathrm{N}$-cadherin expression in comparison with dysplastic naevi and primary melanoma. Membranous expression of the desmosomal cadherin, desmoglein, was not seen in any tumour studied. Frequently, $\beta$ catenin is aberrantly produced in the cytoplasm of cells in dysplastic naevi and metastatic malignant melanoma, with an implied compromise to adhesive function. Furthermore, membranous $\gamma$ catenin expression was not seen in any of the 70 melanocytic tumours studied, implying obligatory transmembrane binding of cadherins to $\beta$ catenin for maintenance of adhesive function.

Conclusions-The most important alterations in membranous cadherin and catenin expression are seen late in the biological progression of melanocytic tumours at the stage of "in transit" or regional lymph node metastasis, with implications for tumour growth, invasion, and dissemination.

(F Clin Pathol: Mol Pathol 1999;52:151-157)

Keywords: cadherin; catenin; melanoma
Melanoma often develops from clinically and histologically well defined precursor lesions. ${ }^{1}$ Expression of different families of adhesion molecules has been reported previously in melanoma, ${ }^{2-4}$ with major changes reported in the progression of normal melanocytes to benign naevi. Further dramatic changes also occur when cells progress from dysplastic naevi or radial growth phase melanoma to biologically late vertical growth phase primary melanoma. ${ }^{2-6}$

There is now compelling evidence to suggest that cadherins play a major role in epithelial cell-cell adhesion, with additional key roles recognised for cell phenotype, differentiation, epithelial/mesenchymal transformation, and invasion. ${ }^{7-9}$ Loss of E-cadherin is associated with high grade morphology of tumours and there is a significant inverse relation between E-cadherin expression and survival in some tumours. ${ }^{10-13}$ Normal cultured human melanocytes express both E-cadherin and P-cadherin, but it is E-cadherin that is primarily responsible for adhesion of melanocytes to keratinocytes. ${ }^{14}$ Transformed melanocytes produce reduced amounts of E-cadherin and exhibit decreased affinity for normal keratinocytes; a role for the loss of cadherin expression in melanoma metastasis has been suggested. ${ }^{14}{ }^{15}$

Cadherins bind to unphosphorylated $\beta$ or $\gamma$ catenin, forming an E-cadherin or P-cadherincatenin unit in the lateral cell membrane, functionally maintaining cell-cell contacts, and providing a link to the actin cytoskeleton through $\alpha$ catenin. A functional interaction has also been reported between phosphorylated $\beta$ catenin and the transcription factors LEF-1 and Tcf-4, proving that there are mechanisms by which cell adhesion molecules can signal directly to the nucleus and potentially influence growth regulating signals. Of interest is the finding that when $\beta$ catenin accumulates in the cytoplasm, as a result of mutations or otherwise, numbers of $\beta$ catenin-LEF- 1 complexes also increase, with the potential for signal transduction ${ }^{16}$ and a role in melanoma progression.

Conflicting data have been published on cadherin expression in primary melanoma, ${ }^{15-17}$ and few reports have documented the expression of P-cadherin, $\beta$ catenin, and $\gamma$ catenin in melanocytic naevi and melanoma. Using immunohistochemistry on paraffin wax processed archival material, and tissue fractionation as well as western blotting of the proteins using fresh frozen metastatic melanoma tumour tissue, we aimed to assess the membranous expression of 
the classic cadherins (E-cadherin, P-cadherin, and $\mathrm{N}$-cadherin) and the desmosomal cadherin, desmoglein, during the progression of melanocytic tumours from dysplastic naevi to stage III metastatic melanoma. We also assessed whether alterations in catenin expression correlated with tumour biology.

\section{Methods}

SECTIONS AND PATIENTS

Tissue was fixed routinely in $10 \%$ buffered formalin and processed through paraffin wax (Shandon PathCentre 16 hour cycle; Shandon, Runcorn, Cheshire, UK). Sections were cut and mounted on APES prepared slides (dried at $37^{\circ} \mathrm{C}$ overnight).

A dysplastic naevus was defined histologically as showing distinct cytological and architectural atypia with elongation of rete ridges and a host response in the dermis. Atypia was graded as mild, moderate, or severe, based on a published scoring system. ${ }^{18}$ Melanomas were allocated into radial or vertical growth phase according to published criteria. ${ }^{19}$ Numbers of cases were as follows: (1) dysplastic naevi ( $\mathrm{n}=30)$; (2) melanoma without metastasis, radial growth phase in situ $(n=10)$, radial growth phase microinvasive $(n=10)$, and vertical growth phase $(n=10)$; and (3) patients with a single "in transit" cutaneous, or small regional lymph node, metastasis (matched primary melanomas with the metastasis, $n=10$ ). Using the TNM classification, no primary tumour was classified greater than $\mathrm{pT} 3 \mathrm{~b}$ and no secondary deposit greater than $\mathrm{pN} 2 \mathrm{~b}$ (that is, clinical stage III).

A

\begin{tabular}{|c|c|c|c|}
\hline $\begin{array}{l}\text { Naevi (type A) } \\
\text { Mild } \\
\text { Moderate } \\
\text { Severe }\end{array}$ & $\begin{array}{l}\text { MEM } \\
::::: \\
\bullet: \bullet \bullet \\
:: \bullet: \bullet\end{array}$ & $\begin{array}{c}\text { MEM/CYTO } \\
\bullet \bullet \\
\bullet \bullet \\
\bullet\end{array}$ & CYTO \\
\hline $\begin{array}{l}\text { Melanoma } \\
\text { RGP in situ } \\
\text { RGP invasive } \\
\text { VGP }\end{array}$ & $\begin{array}{l}88: 88 \\
88: 88 \\
88: 88\end{array}$ & & \\
\hline $\begin{array}{l}\text { Metastasising } \\
\text { melanoma } \\
\text { Primary } \\
\text { Secondary }\end{array}$ & 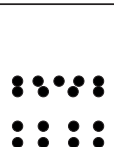 & $\bullet$ & • \\
\hline
\end{tabular}

C

\begin{tabular}{|c|c|c|c|}
\hline $\begin{array}{l}\text { Naevi (type A) } \\
\text { Mild } \\
\text { Moderate } \\
\text { Severe }\end{array}$ & $\begin{array}{l}\text { MEM } \\
\bullet \\
\bullet \bullet \bullet\end{array}$ & 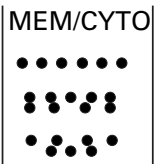 & $\begin{array}{c}\text { CYTO } \\
\bullet \bullet \bullet \bullet ~\end{array}$ \\
\hline $\begin{array}{l}\text { Melanoma } \\
\text { RGP in situ } \\
\text { RGP invasive } \\
\text { VGP }\end{array}$ & $\begin{array}{l}88 \bullet: 8 \\
88 \bullet: 8 \\
88888\end{array}$ & • & \\
\hline $\begin{array}{l}\text { Metastasising } \\
\text { melanoma } \\
\text { Primary } \\
\text { Secondary }\end{array}$ & $\bullet \because \bullet \bullet$ & $\begin{array}{c}\bullet \bullet \\
:::::\end{array}$ & - • • \\
\hline
\end{tabular}

IMMUNOHISTOCHEMISTRY

Sections were microwave pretreated ${ }^{20}$ and immunostained using a standard indirect avidin-biotin complex (ABC) technique. The antibodies used were anti-E-cadherin (HECD-1; 1/100 dilution; Affiniti Research Products, Exeter, Devon, UK, anti-P-cadherin (1/50 dilution; Affiniti Research Products), anti- $\beta$ catenin and anti- $\gamma$ catenin (gifts from K Herrenknecht, University College London, EASAI Institute, UK; optimum dilution $\sim 1 /$ 10), antidesmoglein (against desmogleins 1 and 3; 1/5 dilution; gift from D Garrod, Institute of Biological Sciences, Manchester University, UK) and anti-N-cadherin (1/20 dilution; gift from MJ Wheelock, Department of Biology, University of Toledo, USA). All antibodies were used at concentrations between 0.5 and $3 \mu \mathrm{g} / \mathrm{ml}$. The patterns of immunohistochemical staining (membranous or cytoplasmic) and the percentage of cells stained were noted for each sample by one of us (DSAS). In patients with metastatic disease, statistical comparisons were made for membranous immunoreactivity between the primary and metastatic melanomas. Tumours were allocated a score of $0-3$, depending on the percentages of cells showing membranous immunoreactivity ( 0 , no staining; $1,1-50 \% ; 2$, $50-70 \%$; 3, 70-100\%). Data were analysed by non-parametric means using the Wilcoxon signed ranks test for related samples. The presence of epidermis in all of the skin lesions provided an inbuilt positive control for a membranous pattern of staining for all antibodies

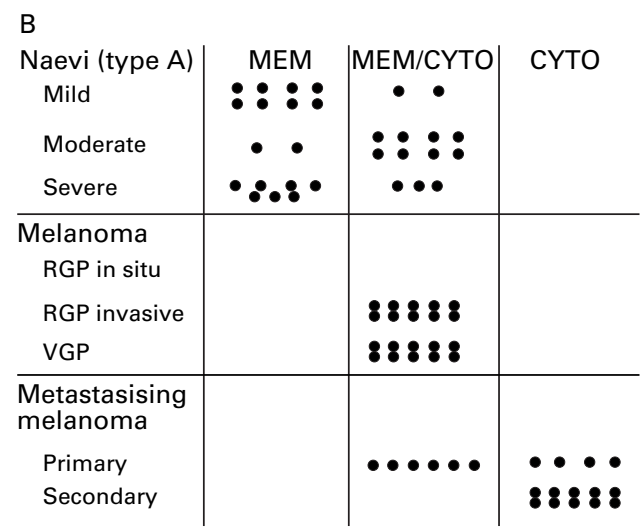

Figure 1 The pattern of immunoreactivity (MEM, membranous; $M E M / C Y T O$, membranous and cytoplasmic, CYTO, cytoplasmic) for (A) E-cadherin, (B) P-cadherin, and $(C) \beta$ catenin in a range of dysplastic naevi and primary and secondary malignant melanomas. Each dot represents one tumour. RGP, radial growth phase; VGP, vertical growth phase. 

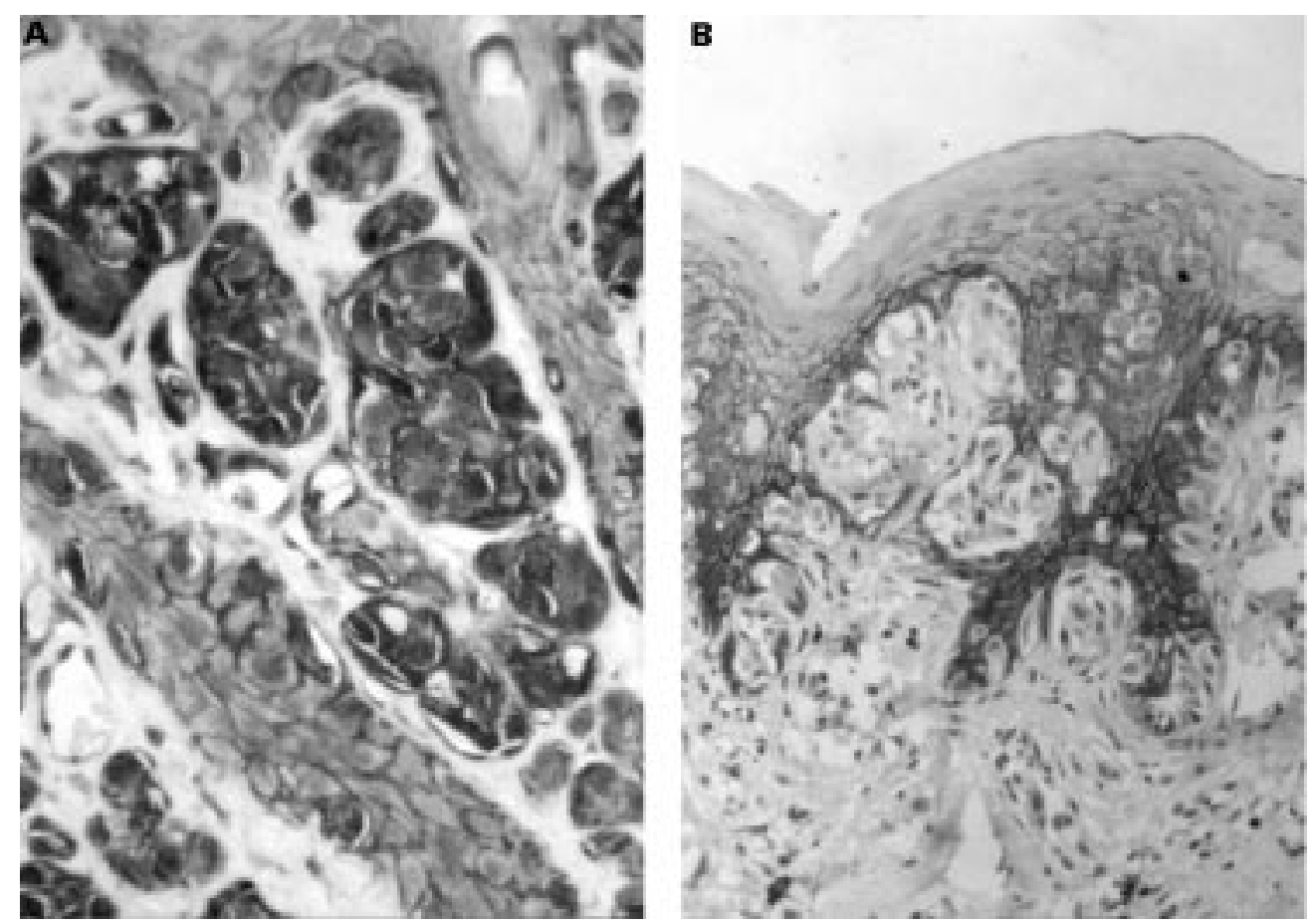

Figure 2 (A) Membranous and strong cytoplasmic immunoreactivity of type A naevocytes with $\beta$ catenin in a dysplastic naevus. Note the membranous positivity of the keratinocytes of the epidermis acting as an internal positive control.

Magnification, $\times 400$. (B) No immunoreactivity is seen in nests of type $A$ naevocytes in a dysplastic naevus with $\gamma$ catenin. Adjacent keratinocytes again act as a positive control. Magnification $\times 100$.

except for $\mathrm{N}$-cadherin, where brain tissue was used as a control.

IMMUNOBLOTTING/TISSUE FRACTIONATION

To study the subcellular localisation of cadherins and catenins in more detail we used tissue fractionation and western blotting. An aliquot of $100 \mathrm{mg}$ of fresh frozen tumour tissue from deposits of metastatic melanoma $(n=4)$ was

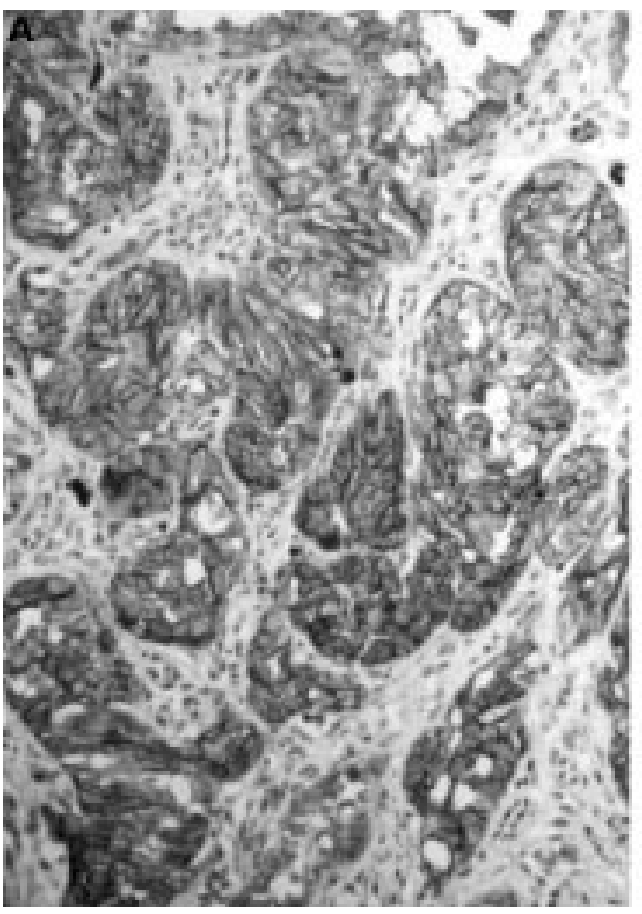

homogenised in $1 \mathrm{ml} 0.32 \mathrm{M}$ sucrose, $5 \mathrm{mM}$ Tris ( $\mathrm{pH} 7.2)$, and protease inhibitor cocktail (Sigma, Poole, Dorset, UK). Tissue was spun at $5500 \times g$ for one hour. The supernatant was removed (cytoplasmic fraction). The pellet was resuspended in sucrose and protease inhibitors, re-centrifuged, and the supernatant discarded. The pellet was resuspended in $9 \mathrm{M}$ urea, $50 \mathrm{mM}$ Tris/ $\mathrm{HCl}$ (pH 7.3), sonicated, and spun

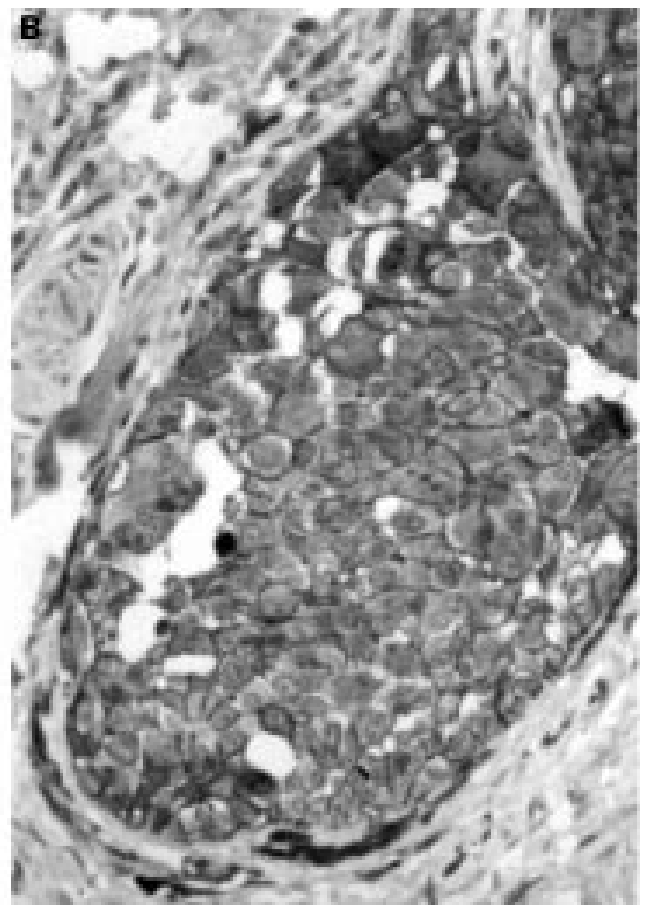

Figure 3 Strong membranous immunoreactivity (100\% of cells) with (A) E-cadherin and (B) P-cadherin in a primary vertical growth phase malignant melanoma. Magnification $\times 100$. 
Table 1 Comparison of membranous immunoreactivity in 10 patients with primary $\left(1^{\circ}\right)$ and matched secondary $\left(2^{\circ}\right)$ melanomas

\begin{tabular}{lllllll}
\hline Patient & $\begin{array}{l}\text { E-cadherin } \\
\left(1^{\circ}\right)\end{array}$ & $\begin{array}{l}\text { E-cadherin } \\
\left(2^{\circ}\right)\end{array}$ & $\begin{array}{l}P \text {-cadherin } \\
\left(1^{\circ}\right)\end{array}$ & $\begin{array}{l}\text { P-cadherin } \\
\left(2^{\circ}\right)\end{array}$ & $\begin{array}{l}\beta \text { Catenin } \\
\left(1^{\circ}\right)\end{array}$ & $\begin{array}{l}\beta \text { Catenin } \\
\left(2^{\circ}\right)\end{array}$ \\
\hline 1 & 3 & 3 & 2 & 0 & 3 & 2 \\
2 & 3 & 3 & 2 & 0 & 3 & 2 \\
3 & 3 & 3 & 2 & 0 & 3 & 2 \\
4 & 3 & 3 & 2 & 0 & 3 & 2 \\
5 & 3 & 3 & 2 & 0 & 3 & 2 \\
6 & 3 & 2 & 2 & 0 & 3 & 2 \\
7 & 2 & 3 & 0 & 0 & 3 & 2 \\
8 & 2 & 2 & 0 & 0 & 2 & 2 \\
9 & 2 & 0 & 0 & 0 & 2 & 2 \\
10 & 1 & 0 & 0 & 0 & 2 & 2 \\
& $\mathrm{p}<0.257$ & & $\mathrm{p}<0.014$ & & $\mathrm{p}<0.05$ &
\end{tabular}

Tumours were allocated a staining score (0-3) depending on the percentage of cells with membranous immunoreactivity. There was no significant loss of membranous E-cadherin immunoreactivity between primary and secondary tumours $(\mathrm{p}<0.257)$ using the Wilcoxon signed ranks test for related samples. Loss of membranous $P$-cadherin and $\beta$ catenin was significant $(p<0.014$ and $\mathrm{p}<0.005$, respectively). at $15000 \times g$ for 10 minutes. The supernatant was removed (particulate/membranous fraction). Samples were balanced for protein content and $10 \mu \mathrm{g}$ of each fraction was loaded on to a $10 \%$ sodium dodecyl sulphate (SDS) polyacrylamide gel and blotted for E-cadherin and P-cadherin (Transduction Laboratories, Lexington, USA) and $\beta$ catenin and $\gamma$ catenin (Santa Cruz Biotechnology, Santa Cruz, USA). Normal oesophageal squamous mucosa was used as a positive control.

\section{Results}

NORMAL CONTROLS

The pattern of immunoreactivity seen in the epidermis of normal skin was membranous staining of keratinocytes in the basal layer for $\mathrm{P}$-cadherin and staining throughout the whole epidermal thickness for E-cadherin, $\beta$ catenin, $\gamma$ catenin, and desmoglein. A fibrillar pattern of immunoreactivity was seen in brain tissue for $\mathrm{N}$-cadherin.

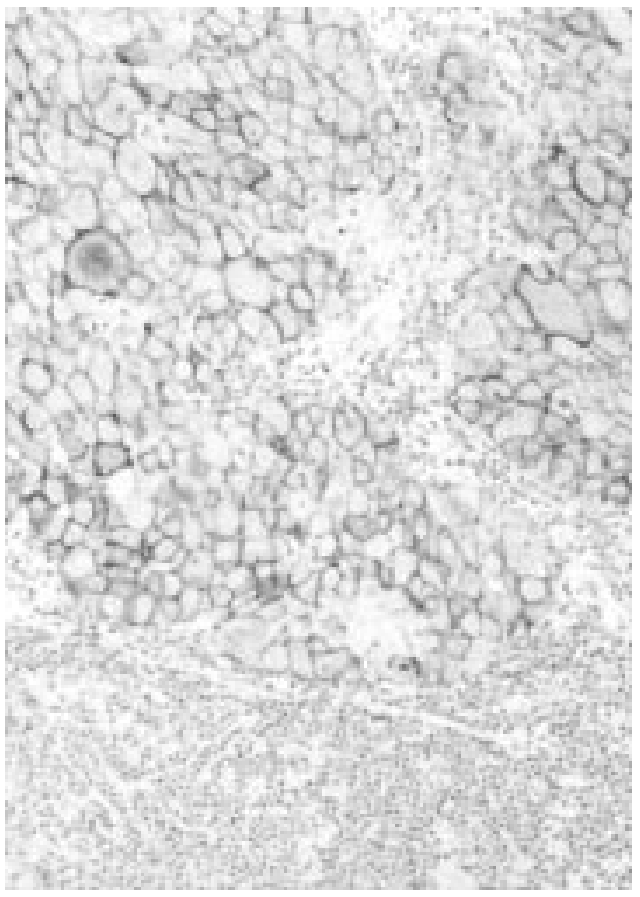

Figure 4 Strong membranous immunoreactivity (100\% of cells) with E-cadherin in melanoma, metastatic to a lymph node. Magnification $\times 100$.

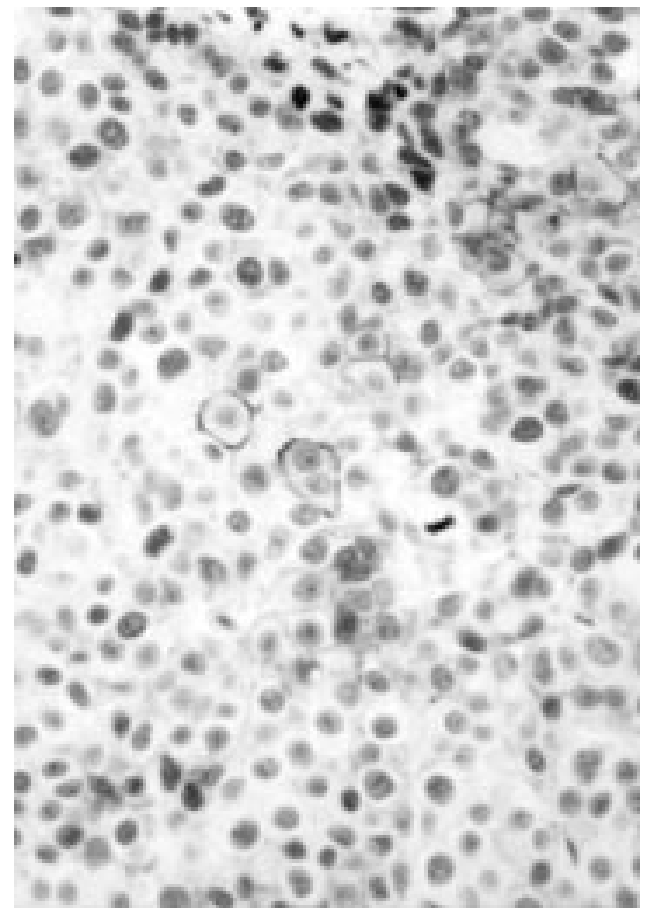

Figure 5 Minimal membranous $N$-cadherin immunoreactivity (1\% of cells) in a primary metastasising vertical growth melanoma. Magnification $\times 400$.

DYSPLASTIC NAEVI

The pattern of immunoreactivity for each antibody in naevi and malignant melanomas is shown graphically in fig $1 \mathrm{~A}-\mathrm{C}$.

In dysplastic naevi, small senile intradermal naevus cells (type B melanocytes) were either negative or showed minimal cytoplasmic immunoreactivity for E-cadherin, P-cadherin, $\mathrm{N}$-cadherin, $\beta$ catenin, and $\gamma$ catenin. Epithelioid junctional and intradermal melanocytes

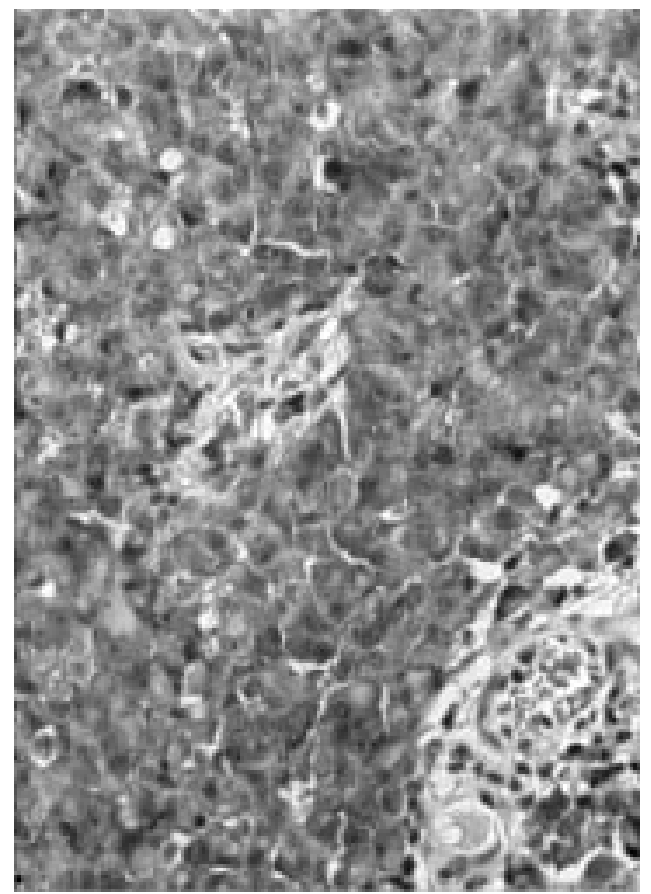

Figure 6 Strong cytoplasmic immunoreactivity (100\% of cells) with $\beta$ catenin in metastatic melanoma. Magnification $\times 400$. 
A

97.4

58.1

39.8

29.0

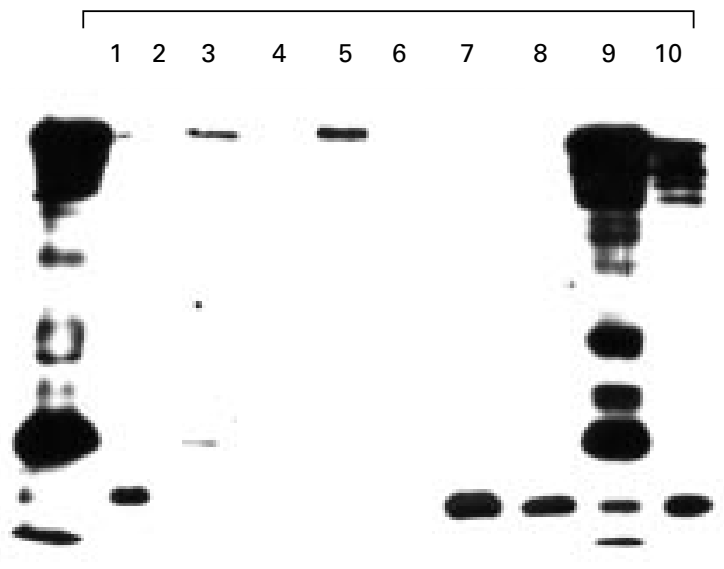

B

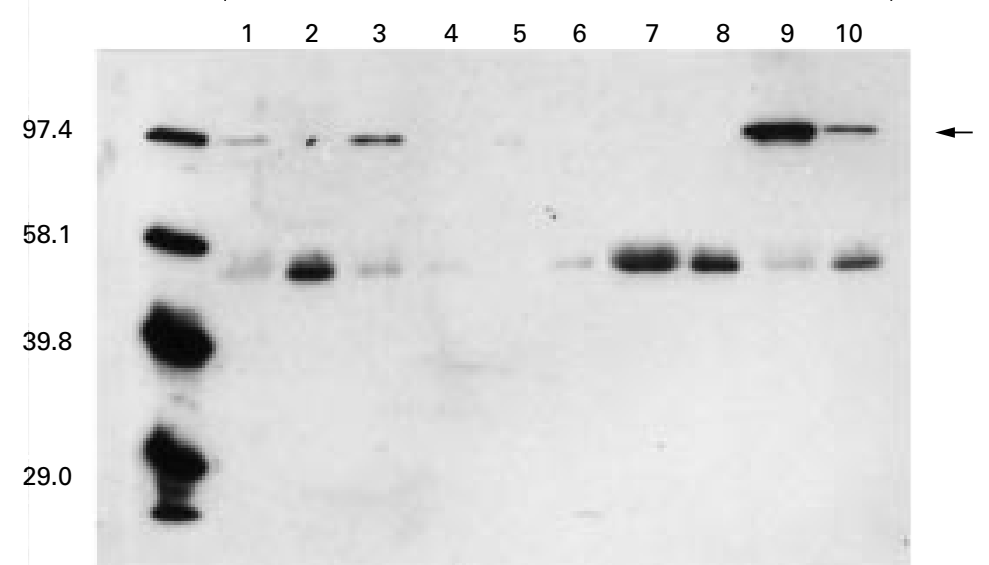

C

97.4

58.1

39.8

29.0
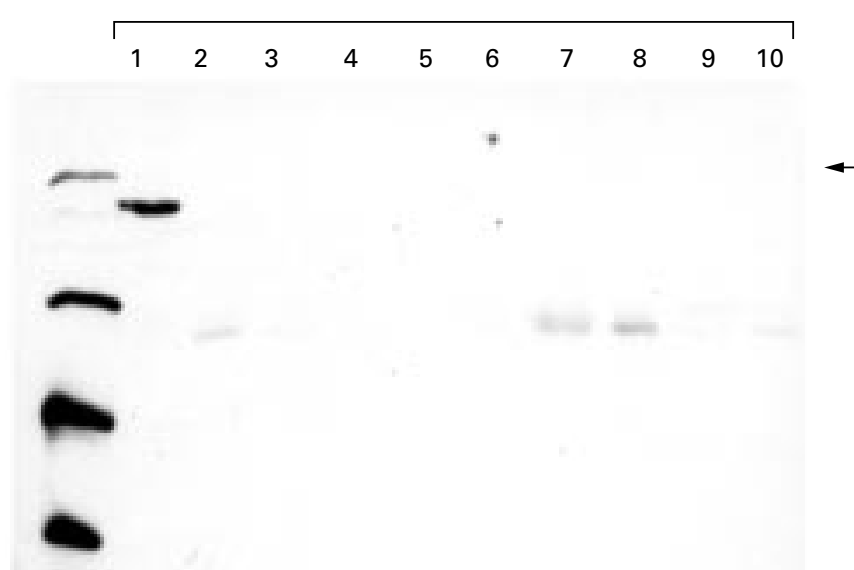

Figure 7 Tissue fractionation and western blotting of normal squamous oesophageal mucosa (positive control; lanes 1 and 2) and four metastatic melanoma samples (lanes 3-10). The membranous cellular fractions were run in lanes with odd numbers and the cytoplasmic fractions in even numbered lanes. (A) As indicated by the arrow, the control and three melanoma samples show strong membranous immunoreactivity with E-cadherin (lanes 1, 3, 5, and 9). One sample shows concomitant cytoplasmic positivity (lane 10). One sample is negative (lanes 6 and 7). (B) As indicated by the arrow, the control and two samples show membranous $\beta$ catenin immunoreactivity (lanes 1, 3, and 9), one also with concomitant cytoplasmic positivity (lane 10). Two samples are negative. (C) No positivity is seen in either cell fraction with $\gamma$ catenin despite a positive membranous control.

(type A melanocytes) showed universal (100\% of cells) strong membranous E-cadherin and $\mathrm{P}$-cadherin immunoreactivity, regardless of the degree of cytological atypia. However, they had predominantly synchronous membranous and cytoplasmic $\beta$ catenin immunoreactivity (fig $2 \mathrm{~A})$. There was no discernible membranous $\mathrm{N}$-cadherin, $\gamma$ catenin (fig $2 \mathrm{~B}$ ), or desmoglein immunoreactivity (30 of 30 patients).

PRIMARY RADIAL AND VERTICAL GROWTH PHASE MALIGNANT MELANOMA

All junctional and intradermal cells of in situ (10 of 10 patients), microinvasive radial growth phase (10 of 10 patients), and vertical growth phase melanomas (10 of 10 patients) showed strong, predominantly membranous E-cadherin and P-cadherin immunoreactivity (fig $3 \mathrm{~A}$ and B), and membranous or cytoplasmic $\beta$ catenin immunoreactivity. However, no membranous $\mathrm{N}$-cadherin, $\gamma$ catenin, or desmoglein immunoreactivity was seen.

\section{MELANOMA WITH EARLY METASTASIS}

Immunohistochemistry

Table 1 gives details of the statistical analysis of the comparison of scores of membranous expression of $\mathrm{E}$-cadherin and $\mathrm{P}$-cadherin and $\beta$ catenin in the primary and matched secondary (metastatic) melanomas in 10 patients.

Only six of 10 patients showed membranous P-cadherin immunoreactivity in the primary melanoma, with significant loss of membranous $\mathrm{P}$-cadherin expression between primary and secondary melanomas $\left(Z=-2.449^{\mathrm{a}}\right.$; $\mathrm{p}<0.014$; table 1 ). No immunoreactivity was seen in primary or secondary melanomas in the remaining four patients. Strong membranous E-cadherin immunoreactivity was seen in all primary melanomas (10 of 10 patients). Six patients showed no change in expression between the primary and matched metastatic melanoma (fig 4), two patients showed minor membranous E-cadherin loss in the metastasis, two patients showed dramatic E-cadherin downregulation with loss of membranous expression in the metastasis, and there was membranous E-cadherin upregulation in one metastasis. This loss of membranous E-cadherin immunoreactivity between primary and secondary melanomas was not significant $\left(Z=-1.134^{\mathrm{a}} ; \mathrm{p}<0.257\right.$; table 1$)$. Minimal membranous $\mathrm{N}$-cadherin immunoreactivity ( $1 \%$ of cells) was seen in three of 10 primary melanomas (fig 5), with striking $\mathrm{N}$-cadherin expression in $70 \%$ of cells in one of 10 metastases. All other samples were negative.

There was significant loss of membranous $\beta$ catenin expression between primary and metastatic melanomas $\left(Z=-2.810^{\mathrm{a}} ; \mathrm{p}<0.005\right.$; table 1$)$. Strong membranous $\beta$ catenin immunoreactivity was seen in most cells in seven of the 10 primary melanomas. Loss of membranous expression was seen in all of the matched metastases (fig 6). Concomitant membranous and cytoplasmic expression was seen in the remaining three primary melanomas, with no change in two, and loss of membranous expression in one patient.

No $\gamma$ catenin or desmoglein immunoreactivity was seen in any of the primary or secondary melanomas. 
Tissue fractionation and western blotting

More detailed subcellular localisation of cadherins and catenins was seen with tissue fractionation and western blotting. Immunoreactivity was seen in the membranous fraction only in the normal squamous mucosa, with E-cadherin, P-cadherin, $\beta$ catenin, and $\gamma$ catenin acting as a positive control.

Three of four metastatic tumour samples showed strong E-cadherin expression in the membranous fraction, but only one of the three showed concomitant expression in the cytoplasmic fraction (fig 7A). Two samples showed strong membranous $\beta$ catenin expression, one with concomitant cytoplasmic expression (the same sample showed concomitant membranous and cytoplasmic E-cadherin expression), and two samples showed no $\beta$ catenin immunoreactivity in either cellular fraction (fig 7B). $\mathrm{P}$-cadherin and $\gamma$ catenin (fig 7C) could not be demonstrated in either cellular fraction of the four samples.

\section{Discussion}

The study of the precursor lesions of metastatic malignant melanoma provides insights into the biological progression of these tumours. Our study on paraffin wax processed material from surgically removed melanocytic tumours has shown that in dysplastic naevi, membranous expression of E-cadherin is related to melanocytic maturity and an epithelioid phenotype, regardless of grade of cytological atypia. ${ }^{16}$ In contrast to a recent publication, ${ }^{17}$ we show that the expression of membranous E-cadherin is largely maintained during malignant transformation to radial growth phase melanoma and with progression to vertical growth phase melanoma and metastasis. Thus, loss of E-cadherin expression is apparently not a universal or inevitable feature of tumour progression, as has been suggested..$^{1521}$ However, we did show significant derangement of P-cadherin expression; the appropriate membranous expression seen in primary vertical growth phase melanomas is significantly altered in metastatic tumours.

Although appropriate membranous E-cadherin expression in most malignant melanomas implies potential preservation of adhesive function, normal cadherin expression does not always equate to normal function, because function can be modified by both the specificity and amount of different cadherins on cell surfaces ${ }^{7}$ and cadherin glycosylation ${ }^{22}$; in addition, it is dependent on intact binding with unphosphorylated catenins. Furthermore, one report has noted that melanomas express more types of novel cadherins than do melanocytes. ${ }^{23}$ In this respect, we have shown "de novo" expression of the neural cadherin, $\mathrm{N}$-cadherin, in a small number of metastasising melanomas. $\mathrm{N}$-cadherin has been found in contacts between melanoma cells in cell lines. ${ }^{24}$ Inappropriately expressed $\mathrm{N}$-cadherin might compete with E-cadherin and P-cadherin for transmembrane binding with available catenins. A role for $\mathrm{N}$-cadherin in the transendothelial migration of melanoma cells in culture has also been suggested. ${ }^{25}$
It is of considerable interest that we have demonstrated aberrant $\beta$ catenin expression, with significant loss of membranous expression seen with progression to melanoma metastasis and inappropriate strong cytoplasmic immunoreactivity, in many dysplastic naevi and secondary melanomas. Early in the gastrulation stage of development, $\beta$ catenin and $\gamma$ catenin translocate to the nucleus and, in association with LEF-1 and Tcf, induce cells to form mobile mesodermal sheets, which are necessary for organogenesis. In normal tissues, $\beta$ catenin is usually bound to membranous cadherins or to the adenomatous polyposis coli (APC) gene product, where it is targeted for destruction. In melanomas, as in some other common tumours, during early cellular transformation the APC gene product might be mutated, thereby increasing the pool of cytoplasmic $\beta$ catenin with the potential for growth regulating signalling to the nucleus. ${ }^{26}$ Stabilisation of $\beta$ catenin is also seen after mutation of the $\beta$ catenin gene. ${ }^{25}$ Therefore, cytoplasmic $\beta$ catenin might be expected to be a feature of rapid tumour growth and biological aggression. In our study, cytoplasmic immunoreactivity was a frequent feature in dysplastic naevi and secondary melanomas, both proliferating and biologically active tumours, but was seen only rarely in radial growth phase melanomas-biologically indolent tumours that show little mitotic activity, no expansile growth, and lack the ability to metastasise. ${ }^{1}$ However, biological progression of melanoma to the vertical growth phase implies more expansile growth with cellular proliferation; surprisingly, the synthesis of cytoplasmic $\beta$ catenin was not a frequent feature of these tumours in our study. We saw no nuclear staining for $\beta$ catenin in our study, as has been reported recently in tumorigensesis in the oesophagus. ${ }^{25}$ It is noteworthy that tumour infiltrating lymphocytes have been shown recently to recognise an antigen encoded by a mutated human gene, namely, the $\beta$ catenin gene. ${ }^{27}$ This might provide new opportunities for therapeutic strategies against melanoma. $^{2829}$

It is of interest that no membranous $\gamma$ catenin or desmoglein could be demonstrated in dysplastic naevi or melanomas. $\gamma$ Catenin is usually co-localised with $\beta$ catenin in epithelial tissues and tumours at cell junctions. Lack of $\gamma$ catenin would imply obligatory transmembrane binding of cadherins to $\beta$ catenin for maintenance of adhesive function. $\gamma$ Catenin is unique in that it links both desmosomal and classic cadherins to the cytoskeleton. Data on squamous epithelial cells ${ }^{30}$ suggest that $\gamma$ catenin must be linked to E-cadherin in the adherens junction before the cell can begin to assemble desmosomal components at regions of cell contact. In the absence of $\gamma$ catenin, adherens junctions can form using only $\beta$ catenin, but such junctions cannot support the formation of desmosomes. At the ultrastructural level, melanocytes and melanoma cells are reported to have no desmosomes and only rudimentary cell junctions, ${ }^{31}$ which might partly be the result of the absence of $\gamma$ catenin. 
In conclusion, we have shown that the greatest changes in cadherin and catenin expression occur at the stage of metastasis of vertical growth phase melanoma, characterised by significant loss of membranous $\mathrm{P}$-cadherin and $\beta$ catenin, minimal membranous E-cadherin loss, and minor de novo membranous $\mathrm{N}$-cadherin expression. No membranous $\gamma$ catenin or desmoglein is seen in melanocytic tumours. These changes, together with cytoplasmic $\beta$ catenin expression in secondary melanomas, imply the loss of adhesive capacity, the potential for nuclear signalling, and hence a role for these cell adhesion molecules in the growth, invasion, and spread of malignant melanoma.

The authors thank $M$ Wheelock for the kind donation of the antibody to N-cadherin used in this study.

1 Clark WH, Elder DE, Guerry D, et al. A study of tumor progression: the precursor lesions of superficial spreading

2 Sanders DSA, Evans AT, Allen CA, et al. Classification of CEA-related positivity in primary and metastatic malignant melanoma. $\mathcal{F}$ Pathol 1994;172:343-8.

3 Johnson JP, Stade BG, Holtzmann B, et al. De novo expression of ICAM-1 in melanoma correlates with increase risk of metastasis. Proc Natl Acad Sci USA 1989;86:641-4.

4 Nesbit M, Herlyn M. Adhesion receptors in human melanoma progression. Invasion and Metastasis 1994;14: $131-46$.

5 Natali P, Nicotra MR, Cavaliere R, et al. Differential expression of ICAM-1 in primary and metastatic melanoma lesions. Cancer Res 1990;50:1271-8.

6 Denton KJ, Stretch JR, Gatter KC, et al. A study of adhesion molecules as markers of progression in malignant melanomas. I Pathol 1992;167:187-91.

7 Steinberg MS, Takeichi M. Experimental specification of cell sorting tissue spreading and specific spatial patterning by quantitative differences in cadherin expression. Proc Natl Acad Sci USA 1994;91:206-9.

8 Takeichi M. Cadherin cell adhesion receptors as a morphogenetic regulator. Science 1991;251:1451-5.

9 Frixen UH, Behren J, Sachs M, et al. E-cadherin mediated cell-cell adhesion prevents invasiveness of human carcinoma cells. F Cell Biol 1991;113:173-85.

10 Dorudi S, Sheffield JP, Poulsom R, et al. E-cadherin expression in coloreetal cancer. An immunohistochemical and in situ hybridisation study. Am f Pathol 1993;142:981-6.

11 Moll R, Mitze M, Frixen UH, et al. Differential loss of E-cadherin expression in infiltrating ductal and lobular breast carcinomas. Am f Pathol 1993;143:1731-42.

12 Siitonen SM, Kononen JT, Helin HJ, et al. Reduced $\mathrm{E}$-cadherin expression is associated with invasiveness and unfavourable prognosis in breast cancer. Am f Clin Pathol 1996;105:394-402.
13 Schipper JH, Frixen UH, Behrens J, et al. E-cadherin in squamous carcinomas of head and neck: inverse correlation with tumour differentiation and lymph node metastasis. Cancer Res 1991;51:6328-37.

14 Tang A, Eller MS, Hara M, et al. E-cadherin is the major mediator of human melanocyte adhesion to keratinocytes in vitro. F Cell Sci 1994;107:983-92.

15 Danen EHJ, Devries TJ, Morandini R, et al. E-cadherin expression

16 Cowley GP, Smith ME. Cadherin expression in melanocytic naevi and malignant melanomas. F Pathol 1996;179:183-7.

17 Silye R, Karayiannakis KN, Syrigos S, et al. E-cadherin/ catenin complex in benign and malignant melanocytic lesions. F Pathol 1998;186:350-5.

18 Black WC, Hunt WC. Histologic correlation with the clinical diagnosis of dysplastic naevus. Am f Surg Pathol 1990;14:44-52.

19 Guerry IVD, Synnestvedt M, Elder DE, et al. Lessons from tumor progression: the invasive radial growth phase of melanoma is common, incapable of metastasis, and indolent. F Invest Dermatol 1993;100:342S-5S

20 Shi SR, Key ME, Kalra KL. Antigen retrieval in formalin fixed paraffin embedded tissues: an enhancement method for immunohistochemical staining based on microwave for immunohistochemical staining based on microwave 39:741-7.

21 Seline PC, Norris DA, Horikawa T, et al. Expression of E and P-cadherin by melanoma cells decreases in progressive melanomas and following ultraviolet radiation. F Invest Dermatol 1996;106:1320-4

22 Yoshimura M, Ihara Y, Matsuzawa Y, et al. Aberrant glycosylation of E-cadherin enhances cell adhesion to suppress metastasis. F Biol Chem 1996;271:13811-15.

23 Matsuyoshi N, Tanaka T, Toda K, et al. Identification of novel cadherins expressed in human melanoma. F Invest Dermatol 1997;108:908-13.

24 Sandig M, Voura EB, Kalnins VI, et al. Role of cadherins in the transendothelial migration of melanoma cells in the transendothelial migration of melanom
culture. Cell Motil Cytoskeleton 1997;38:351-64.

25 Rubinfeld B, Robbins P, El-Gamil M, et al. Stabilisation of $B$-catenin by genetic defects in melanoma cell lines. Science 1997;275:1789-92.

26 Bailey T, Biddlestone L, Shepherd N, et al. Altered cadherin and catenin complexes in the Barrett's esophagusdysplasia-adenocarcinoma sequence: correlation with disease progression and dedifferentiation. Am f Pathol 1998;152:135-44

27 Robbins PF, El-Gamil M, Li YF, et al. A mutated $\beta$-catenin gene encodes a melanoma-specific antigen recognised by tumour infiltrating lymphocytes. F Exp Med 1996;183: 1185-92.

28 Maeurer MJ, Storkus WJ, Kirkwood JM, et al. New treatment options for patients with melanoma; melanoma derived T-cell epitope based peptide vaccine. Melanoma Res 1996;6:1-24.

29 Wang RF, Rosenberg SA. Human tumour-antigens recognised by T-lymphocytes for cancer therapy. 7 Leukoc Biol 1996;60:296-309.

30 Lewis JE, Wahl JK, Sass KM, et al. Cross talk between adherens junctions and desmosomes depends on plakoglobin. $f$ Cell Biol 1997;136:919-34.

31 Mazur MT, Katzenstein A-LA. Metastatic melanoma; the spectrum of ultrastructural morphology. Ultrastruct Pathol $1980 ; 1: 337-56$ 